\title{
Discussion on Mechanical Engineering Reliability Optimization Design
}

\author{
Zhang Bo \\ NanChang Institute of Science \& Technology
}

\begin{abstract}
Industrial Engineering is a cross-disciplinary that organically combines technology and management. As we all know, it can put an end to all kinds of waste and effectively improve the productivity and economic efficiency. To enhance its market competitiveness, the domestic enterprises have made deep research on ways of upgrading labor productivity and reducing kinds of wastes one after another. Therefore, the applied research on Industrial Engineering in domestic enterprises especial large enterprises, as an issue with high theoretical and practical significance, has been pushed into an unprecedented prominent position. And at the same time, Industrial Engineering is also widely researched and applied in non-manufacturing areas like government management, hospitals and service industries. This paper analyzes the developing trade in foreign countries and the using satiation in domestics of Industrial Engineering by using the basic theory of it, and make research and improvement on mechanical engineering by using the idea of Industrial Engineering and through working research and standardization management.
\end{abstract}

\section{Keywords- Industrial Engineering; Mechanical} Engineering; Reliability; Optimization Design

\section{INTRODUCTION}

Since the British industrial revolution in 1760s, the mechanics with the steam engine, the internal combustion engine and electric motor as their source of power promoted the rapid development of manufacturing and transportation, and people began to enter the modern civilized society. In 20th century, the invention of computer and the combination of automation technology, information technology and sensor technology brought the machine into the stage of complete modernization. Robots, CNC machine tools, high-speed vehicles, heavy machinery and other large quantity of advanced machinery and equipment have accelerated the progress of human society, and the machinery has already become one of the five elements of modern social production and services (people, capital, energy, materials, machinery). So consequently, accelerate developing of mechanism engineering becomes the basis and premise to fulfill industrialization and modernization in our country and it is the only way for the take-off of Chinese industrial.

Since the reform and opening up, China's socialist market economy has been rapidly developed, and the level of industrial mechanization is higher and higher. At present, the mechanical engineering plays a very important role in various fields of economic construction, and it is an important factor for the development of the national economy. So, people should pay high attention on optimization design of mechanical engineering reliability. Mainly from several aspects, this paper states some problems that are easily arise in optimization design of machinery engineering reliability and presents some shortages of researching in this area current in our country, and to provide references for enterprises of machinery manufacturing.

By using the theory of industrial engineering, the paper introduces the basic concepts and discipline system of mechanical engineering, analyzes the development of mechanical engineering is the need of social production and social progress, describes that the development of mechanical engineering makes great impact on the social productive forces, industrial structure, mode of production and the social ideology, and points out that the development of it is the trend of the 21 st century.

\section{THEORIES AND METHODS OF INDUSTRIAL ENGINEERING}

Developing on the basis of scientific management, the industrial engineering (IE) emphasizes on integrate 
improvement of labor productivity, reduction of production costs and assurance of product quality, and makes the resulting system run at its best and to obtain the highest overall efficiency.

Taylor is the founder of not only the IE but also the scientific management, IE in his discourse in "Principles of Scientific Management” was just a part of it. Until 1911, scientific management theorists began to use IE term, and in 1917 the IE association was established in the United States. Many enterprises began to set IE department to take responsibility on working research. After then, IE took part from the scientific management gradually, and from the view of its developing history, Taylor's scientific management is the predecessor of it, and so, two of them are in the same strain. From the view of IE's function, it is the communication bridge between technology and management. Since the development of information technology in 1970s, the practitioners of management introduced IE into the research field of industrial macroscopic systems and underwent a relationship with the industrial management function of government.

IE is an engineering subject which makes integrated planning, designation, improvement, controlling and innovation on the elements of people, materials, equipment, information and energy. By using natural sciences, mathematics, social sciences, and the theory and methods of engineering and technology in particular, IE provides a strong technical support to manufacturing, management and service system for implementing the management object of low cost, high efficiency and cost-effectiveness.

\section{INTRODUCTION OF MECHANICAL ENGINEERING}

Mechanical Engineering is an applied disciplines with theoretical foundation of related Natural Sciences represented by mathematics and mechanics and etc., and Technological Sciences represented by Design, materials science, manufacturing science; it researched and resolves the theoretical and practical problems in process of developing and designing, manufacturing, installing, using and maintaining kinds of machinery, by combining with technical experiences accumulated from production practices.

In general, mechanical engineering science can be divided into two disciplines: study of machinery and mechanical manufacturing engineering, which correspond to two stages of mechanical systems experienced from concept to realization: design and manufacture. The components of mechanical engineering science are as below: 


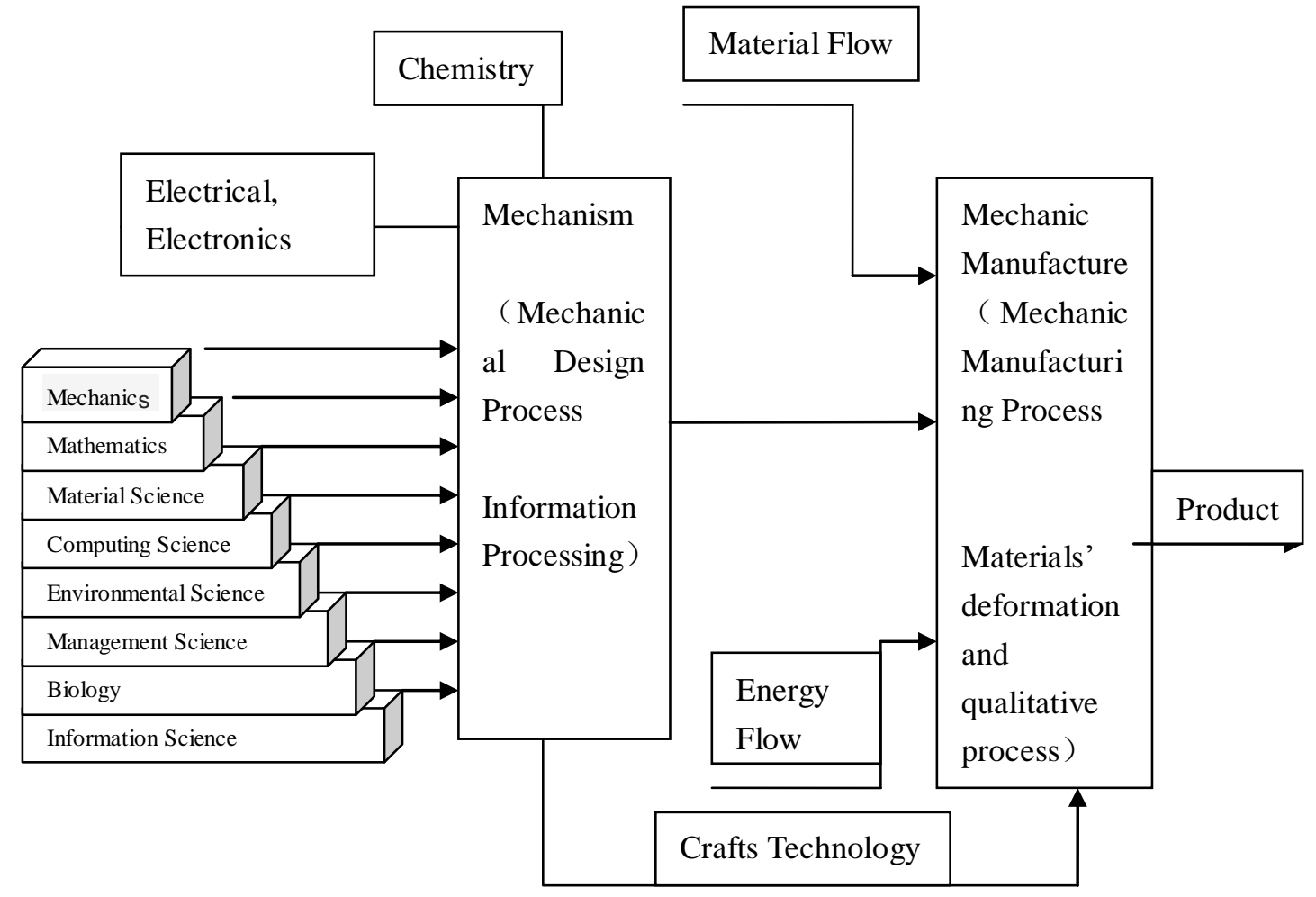

Figure 1. Consisting of Mechanical Engineering Sciences

Mechanics is a basic technology discipline that makes functional comprehensive and also quantitative description on machinery and takes control of its performance. The main task of it is to translate all related subjects' knowledge and techniques and also all kinds of information into necessities needed by the development of society, production and scientific technology and the mechanical design that can be accepted by machinery manufacturing technology through creative thinking process. Machinery manufacturing is a process to accept the direction and information output from the design and also to process the product that meet the design requirements. Consequently, the mechanical manufacturing is a discipline to study mechanical manufacturing systems and processes means.

\section{UsAGE OF RELIABILITY DESIGN IN MACHINERY}

\section{A. Reliability design in designing part}

Design of mechanical product is a very complex process, mainly includes two aspects: one is the overall assembly design, and another is design for assembled parts. For the entire product, it can be used as an overall design, there are two specific design methods: one is to firstly get knowledge of product's entire system and make detailed analysis of the reliability of the product for each part, and then to infer the reliability of the product, and it is must be ensured that the overall reliability of the design can meet the standards of related design; another is to implement the overall reliability analysis separately into various parts of the design, so that if the reliability of the design meet the relevant indicators, the overall product's reliability can be ensured. When people design a single part, they shall choose to use those parts that meet the relevant national regulations or has large-scale usage in the market, and at the same time, different design methods shall be used in parts with different importance, reliability testing must be taken in particular for the parts in the key portion. In order to ensure product quality and reliability, testing should be taken repeatedly until it reaches the standard.

\section{B. Reliability Design in Manufacturing Process}

The manufacturing sector is key to ensuring the quality of the product, so people must pay much attention on the manufacturing sector's reliability design. When making manufacturing sector reliability design, people should not 
only focus on the processing equipment reliability design but also pay attention to scientific selection for processing technology and processes. If taking the overall process of products' processing understood as a system, then any of the processing technology and procedures are subsystems in the system. Consequently, reliability design for each subsystem should be considered from all direction, so as to ensure the reliability of subsystems can meet the relevant requirements, these subsystems can form a complete whole through scientific sorting and assembly. Then the professionals calculate the overall reliability index through scientific statistical methods.

\section{V.CONCLUSION}

For now, the reliability index is not considered in general mechanical engineering design, so general mechanical engineering is not able to reflect the product's truly reliability, for the specific design generally ignores the cost, size and so on. When carrying out reliability design, if people only purpose on meeting the reliability design, they can not make machinery to achieve satisfactory results, so they should take full account of the reliability of the design in accordance with the needs and combine reliability with performance optimization of the mechanical engineering as much as possible, so as to the best results can be achieve.

Conclusions of this essay are as follow:

(1) In theory, the paper studies the meaning of IE and summarizes the basic principle and common methods of it. As practice shows, IE is able to make elements input by production system be used in an efficient way, reduce cost, ensure quality and safety, and upgrade the production efficiency, so that to make enterprises get the best benefits.

(2) The paper elaborates easily accoutered problems in the mechanical engineering reliability optimization design and put forward China's current lack of research in this area, and then provides references for machinery manufacturing enterprises.

\section{REFERENCES}

[1] Salvendy G. Handbook of industrial engineering[M]// Wiley, 2001.

[2] Bidanda B, Hosni Y A. Reverse engineering and its relevance to industrial engineering: A critical review[J]. Computers \& Industrial Engineering, 1994, 26(2):343-348.

[3] Bidanda B, Hosni Y A. Reverse engineering and its relevance to industrial engineering: A critical review $[\mathrm{J}]$. Computers \& Industrial Engineering, 1994, 26(2):343-348.

[4] Maynard H B, Zandin, Kjell B. Maynard's industrial engineering handbook[M]McGraw-Hill, 2001.

[5] Maynard H B, Zandin K B. Maynard's industrial engineering handbook[J]. Maynards Industrial Engineering Handbook, 2001.

[6] Maynard, H. B., \& Zandin, K. B. (2001). Maynard's industrial engineering handbook. Maynards Industrial Engineering Handbook.

[7] Kahraman, C. (2006). Fuzzy applications in industrial engineering. Studies in Fuzziness and Soft Computing, 201.

[8] Maynard, H. B., \& Zandin, Kjell B. (2001). Maynard's industrial engineering handbook. McGraw-Hill.

[9] Toto R, Nguyen H. Flipping the Work Design in an industrial engineering course[C] 2013 IEEE Frontiers in Education Conference (FIE). IEEE, 2009:1-4.

[10] Maynard, Harold Bright, and K. B. Zandin. "Maynard's industrial engineering handbook." Maynards Industrial Engineering Handbook (2001).

[11] Kahraman C. Fuzzy Applications in Industrial Engineering[J]. Studies in Fuzziness and Soft Computing, 2006, 201.

[12] Toto, R., \& Nguyen, H. (2009). Flipping the Work Design in an industrial engineering course. 2013 IEEE Frontiers in Education Conference (FIE) (pp.1-4). IEEE. 